\title{
Author Correction: Measuring dynamic social contacts in a rehabilitation hospital: effect of wards, patient and staff characteristics
}

\section{Audrey Duval, Thomas Obadia, Lucie Martinet, Pierre-Yves Boëlle $\mathbb{D}^{\mathbb{B}}$, Eric Fleury, Didier Guillemot, Lulla Opatowski, Laura Temime, \& I-Bird study group}

Correction to: Scientific Reports https://doi.org/10.1038/s41598-018-20008-w, published online 26 January 2018

The Supplementary Material file that accompanies this Article contains an error in equations 3 and 5 and the paragraphs that follow them. Equation 3 and the paragraph below it:

$$
\forall_{c, c} D C D(c)=\frac{1}{N_{c}} \sum_{i \epsilon c} \frac{1}{D_{i}} \sum_{t=1}^{D_{i}} \sum_{j \in H(t)} D C D(i, j, t)
$$

Where $c$ is the category (eg. HCW, patients, etc.), $N_{c}$ is the number of individuals $i$ belonging to category $c, D_{i}$ the number of days of presence of individual $i$ in the hospital, $\mathrm{H}(\mathrm{t})$ is the ensemble of all individuals present in the hospital on day $t$, and $D C D(i, j, t)$ the cumulative duration of CPIs on day $t$ between individuals $i$ and $j$.

should read:

$$
\forall_{c, c} D C D(c)=\frac{1}{N_{c}} \sum_{i \epsilon c} \frac{1}{H} \sum_{j \in H} \frac{1}{D_{i, j}} \sum_{t \in D_{i, j}} D C D(i, j, t)
$$

Where $c$ is the category (eg. HCW, patients, etc.), $N_{c}$ is the number of individuals $i$ belonging to category $c, D_{i, j}$ the number of days of contact between $i$ and $j$ in the hospital, $H$ is the ensemble of all individuals present in the hospital, and $D C D(i, j, t)$ the cumulative duration of CPIs on day $t$ between individuals $i$ and $j$.

Equation 5 and the paragraph below it:

$$
\forall\left(w, c_{1}, c_{2}\right), w D C D\left(c_{1}, c_{2}\right)=\frac{1}{N_{w, c 1}} \sum_{i=1}^{N_{w, c 1}} \frac{1}{D_{i}} \sum_{t=1}^{D_{i}} \sum_{j=1}^{N_{c 2}} D C D(i, j, t)
$$

Where $c_{1}$ and $c_{2}$ are two categories, $w$ is the ward number, $N_{w, c l}$ is the number of individuals $s$ belonging to category $c_{1}$ (staff categories or patients), an $D_{i}$ is the number of days of presence of individual $i$ in the hospital, $N_{c 2}$ is the number of individuals from category $c_{2}$ in the hospital, and $D C D(i, j, t)$ is the daily cumulative duration of CPIs of two individuals $i$ and $j$ on day $t$.

should read: 


$$
\forall\left(w, c_{1}, c_{2}\right), w D C D\left(c_{1}, c_{2}\right)=\frac{1}{N_{w, c 1}} \sum_{i=1}^{N_{w, c 1}} \frac{1}{N_{c 2}} \sum_{j=1}^{N_{c 2}} \frac{1}{D_{i, j}} \sum_{j=1}^{D_{i, j}} D C D(i, j, t)
$$

Where $c_{1}$ and $c_{2}$ are two categories, $w$ is the ward number, $N_{w, c 1}$ is the number of individuals $s$ belonging to category $c_{1}$ (staff categories or patients), and $D_{i, j}$ is the number of days of contact between $i$ and $j$ in the hospital, $N_{c 2}$ is the number of individuals from category $c_{2}$ in the hospital, and $D C D(i, j, t)$ is the daily cumulative duration of CPIs of two individuals $i$ and $j$ on day $t$.

(c) (i) Open Access This article is licensed under a Creative Commons Attribution 4.0 International (c) License, which permits use, sharing, adaptation, distribution and reproduction in any medium or format, as long as you give appropriate credit to the original author(s) and the source, provide a link to the Creative Commons license, and indicate if changes were made. The images or other third party material in this article are included in the article's Creative Commons license, unless indicated otherwise in a credit line to the material. If material is not included in the article's Creative Commons license and your intended use is not permitted by statutory regulation or exceeds the permitted use, you will need to obtain permission directly from the copyright holder. To view a copy of this license, visit http://creativecommons.org/licenses/by/4.0/.

(C) The Author(s) 2020 


\section{Consortia}

\section{I-Bird study group}

Anne Sophie Alvarez, Audrey Baraffe, Mariano Beiró, Inga Bertucci, Camille Cyncynatus, Florence Dannet, Marie Laure Delaby, Pierre Denys, Matthieu Domenech de Cellès, Antoine Fraboulet, Jean-Louis Gaillard, Jean-Louis Herrmann, Boris Labrador, Jennifer Lasley, Christine Lawrence, Judith Legrand, Odile Le Minor, Caroline Ligier, Karine Mignon, Catherine Sacleux, Jérôme Salomon, Marie Perard, Laure Petit, Laeticia Remy, Anne Thiebaut, Damien Thomas, Philippe Tronchet, Isabelle Villain 